\title{
Joining Thin Sheet Aluminum Using Mechanical Clinching Process
}

\author{
Zamzuri Hamedon, Mohd Nor Fikry Jamaluddin, and Muhammad Nafis Osman Zahid
}

\begin{abstract}
In this study, a thin aluminum sheet are to be joined by mechanical clinching. The diameter of the die and stroke of the punch are controlled whereas the thickness of the sheets, diameter of the punch and speed of the machine are fixed in order to obtain the best results. It was found that mechanical clinching has superior fatigue strength due to the large yield stress of the sheets and relaxation of the stress concentration. The interlocking between the sheets, the thinning of the sheet and the fracture were observed.
\end{abstract}

Index Terms-Mechanical clinching, plastics deformation, fracture, joining.

\section{INTRODUCTION}

The reduction in weight of automobile parts is a key target in improving the fuel consumption of cars. Manufacturer tend to used lighter, thinner and stronger material such as aluminum, CFRP and high strength steels. Joining of this material became problems with traditional joining method e.g welding, brazing, riveting etc. In the present manufacturing of automobiles, resistance spot welding of three steel sheets comes up to one third of total welded joints, while it is not easy to find appropriate welding conditions for thin sheets. For mechanical joining with screws and rivets, pre-drilling operations are needed and stress concentration appears around edges of holes. Thus, joining by mechanical clinching for certain parts of the vehicle body are widely applicable, especially when joining two different materials [1]. Mechanical clinching initially using cutting and upsetting of sheets with rectangular tools [2]; then improved to become a joining process using an interlock without cutting [3]. Clinching is also used in furniture and computer industries, in different kind household appliances as well as in ventilation and air conditioning products. Since the nineties, a lot of work has been done in the field of light-frame housing. Traditional joining methods for sheet metal frames are based on additional joining elements such as screws, pegs, rivets, bolts and nuts, in addition to which fusion welding has also been employed [4]. Hemming is also applied to join the high strength steel sheet for automotive parts [5]. Clinching has been studied as a potential joining method for frames, mainly because it helps avoid the use of additional accessories.

There are different methods for producing a clinched joint depending on the toolmakers. Therefore, there are different

Manuscript received October 6, 2016; January 7, 2017. This work was supported in part by the University Malaysia Pahang, under Grant RDU1403119 and RDU1403128.

The authors are with University Malaysia Pahang, 26600 Pekan Pahang, Malaysia (e-mail: Zamzuri@ump.edu.my, Fikryjamaludin@gmail.com, Nafis@ump.edu.my). ways of categorizing the clinch joining process depending on issues such as geometry, cutting of the material and the number of stage. Mori et al. [6] used self-pierce rivet to join multiple dissimilar sheet.

Consideration of the die diameter;

$$
D_{D} \leq t_{1}+D_{P}+t_{2}
$$

where,

$$
\begin{array}{ll}
D_{D}=\text { Die diameter } & t_{1}=\text { Thickness of upper sheet } \\
D_{P}=\text { Punch diameter } & t_{2}=\text { Thickness of lower sheet }
\end{array}
$$

The die diameter must less or equal to the summation of thickness of upper sheet, punch diameter and also thickness of lower sheet to ensure that the interlocking to happen and if the die diameter is more the summation, it may cause the upper and lower sheet will not join. Fig. 1 showed the neck fracture and button separation mode defects due to insufficient size of combination between punch and dies.

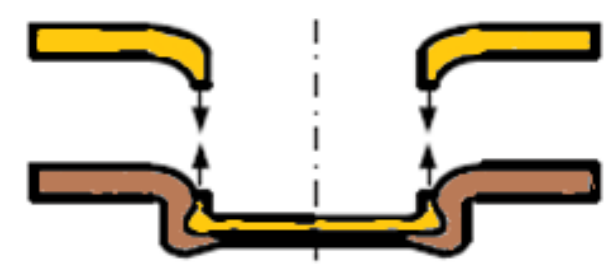

(a) Neck fracture mode

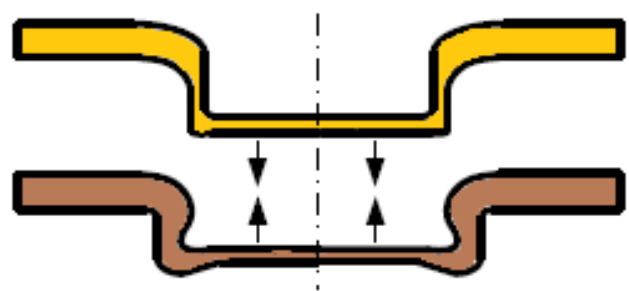

(b) Button separation mode.

Fig. 1. The defects of failure.

For joining using mechanical clinching method, the best result is obtained when having highest interlocking, less thinning and no fracture at the sheets. The results can be obtained by having the die diameter less or equal to the summation of thickness of upper sheet, punch diameter and also thickness of lower sheet. This condition is to ensure that the interlocking to happen however if the die diameter is less the summation, it may cause the upper and/or lower sheet to fracture and if the die diameter is less the summation the sheets will not join.

\section{EXPERIMENTAL SETUP}

Fig. 2 illustrates the die set used. The die set consist of 
upper shoe, lower shoe, punch plate, die plate, punch and die. The punch is fix at the punch holder and die insert is replaceable mounted at the die plate. The stripper plate is used to release the sheet form the punch and also function to clamp the sheets during the clinching process. The 80 ton mechanical press machine model Chin Fong OCP-80 was used for this study. Fig. 3 showed the set-up of the die on the press machine.

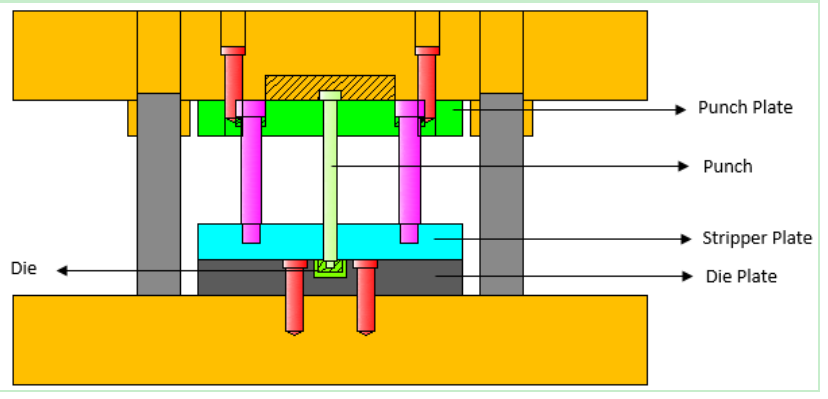

Fig. 2. The design of die.

In this study, sheet thickness, punch diameter, depth of the die were fixed while die diameter, and punch stroke are control in order to obtain the optimized results. Material of aluminum 6061 sheet with $1 \mathrm{~mm}$ thickness, punch diameter is made of pre-harden steel with diameter $5.5 \mathrm{~mm}$ and depth of the die is $2.0 \mathrm{~mm}$ were used. When the punch diameter is 5.5 $\mathrm{mm}$ and the thickness for the sheet is $1 \mathrm{~mm}$, the clearance will be $2 \mathrm{~mm}$ at left and right side and accumulated to $9.5 \mathrm{~mm}$.

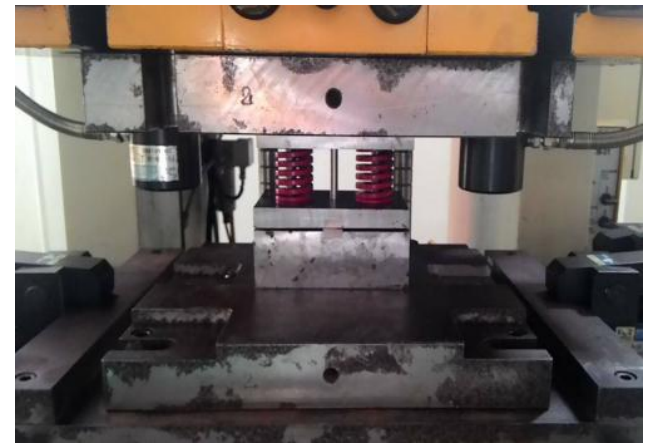

Fig. 3. Set-up of die on press machine.

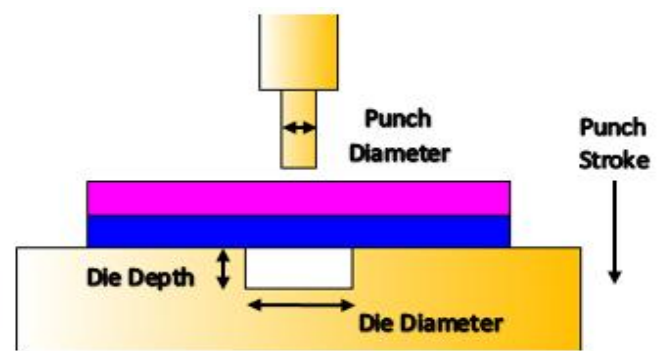

Fig. 4. The parameters that must be emphasis in this experiment.

\begin{tabular}{ccccc}
\multicolumn{4}{c}{ TABLE I: PARAMETERS USED IN THIS RESEARCH } \\
\hline Punch & Die & Sheet & Die & Punch \\
Diameter & Depth & Thickness & Diameter & Stroke \\
\hline & & & & $3.6 \mathrm{~mm}$ \\
& & & $3.7 \mathrm{~mm}$ \\
$5.5 \mathrm{~mm}$ & \multirow{2}{*}{$2.0 \mathrm{~mm}$} & \multirow{2}{*}{$1.0 \mathrm{~mm}$} & $9.00 \mathrm{~mm}$ & $3.8 \mathrm{~mm}$ \\
& & & $9.50 \mathrm{~mm}$ & $3.9 \mathrm{~mm}$ \\
& & & $4.0 \mathrm{~mm}$ \\
& & & $4.1 \mathrm{~mm}$ \\
& & & $4.2 \mathrm{~mm}$
\end{tabular}

Therefore, the range for die diameter are between $9.0 \mathrm{~mm}$ to $9.5 \mathrm{~mm}$ are chosen in order to obtain the interlocking between first and second sheet and also to prevent from the defect from occur For the die depth, $2 \mathrm{~mm}$ is considered is due to the thickness of 2 sheets in order to ensure the interlocking occurred at minimum stroke of the machine. Fig. 4 illustrates the significant parameter considered in this study. The parameter for the experiment is shown in Table I.

\section{RESULTS AND DISCUSSION}

Interlock between two sheets is the main result to analyze from this study. Interlocking is the condition that produced from the movement of sideways between two sheets metal when forces are applied between punch and die. This interlock is ensured the strength of the joined material. Thus the die diameter, die depth, punch diameter and punch stroke must be emphasis to control the interlocking button. Fig. 5 shows process of interlocking between upper sheet and lower sheet. Fig. 6 shows the interlocking area after cross section.
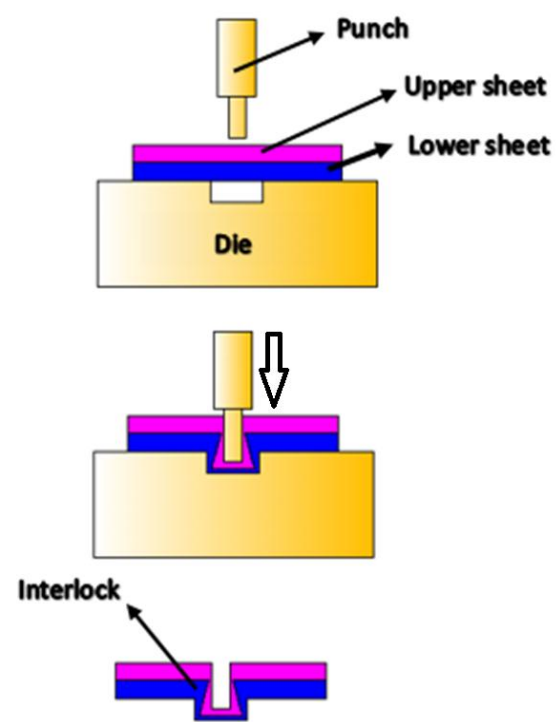

Fig. 5. Process of interlocking between upper sheet and lower sheet.

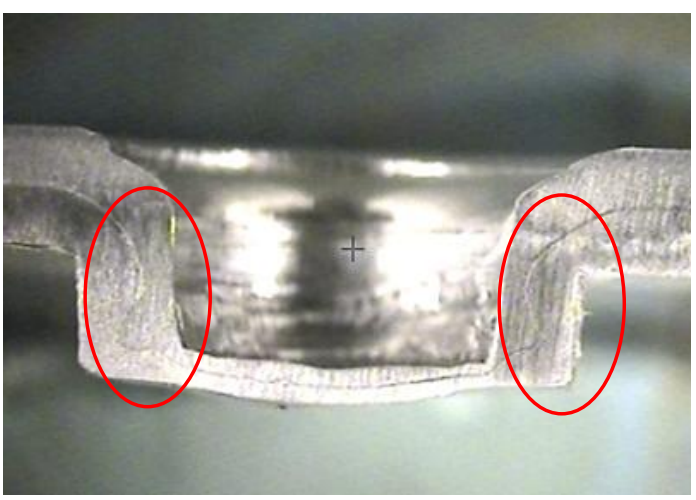

Fig. 6. Interlocking area.

Fig. 7 shows the image of the sheets after the clinching process is performed. From this clinched sheets, interlocking and thinning are measured while fractured can be clearly seen if occured. The joined sheets were cut then polish before measurement was taken. To obtain better result, 3 axis video measurement system with accuracy $0.005 \mathrm{~mm}$ was used as shown in Fig. 8. 


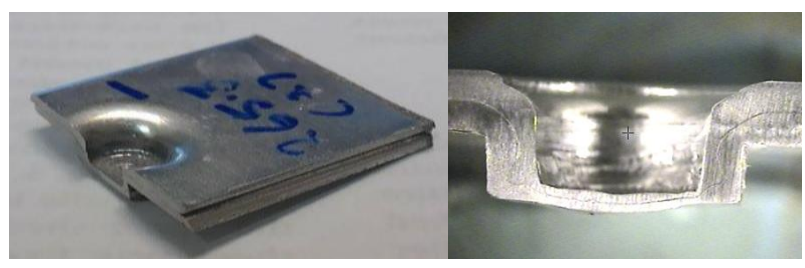

Fig. 7. Aluminum sheets after clinching process.

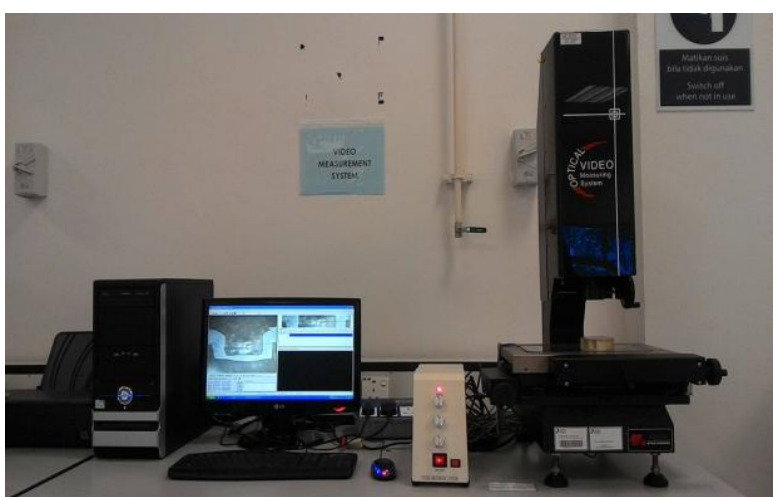

Fig. 8. Video measuring system to measure the interlocking, side thickness and bottom thickness.

Fig. 9 shows the thickness of interlocking at the side wall. Fig. 10 illustrates the effect of punch stroke and die diameter on the interlocking. Die with diameter of $9.0 \mathrm{~mm}, 9.2 \mathrm{~mm}$ and $9.5 \mathrm{~mm}$ were used. The results showed that the interlocking are minimum when stroke at $3.6 \mathrm{~mm}$ and almost consistent when punch stroke are $3.8 \mathrm{~mm}$ until $4.0 \mathrm{~mm}$ and $4.2 \mathrm{~mm}$ for die size of $9.2 \mathrm{~mm}$ and $9.5 \mathrm{~mm}$. The maximum interlocking for die size $9.2 \mathrm{~mm}$ and $9.5 \mathrm{~mm}$ are at punch stroke $4.1 \mathrm{~mm}$. For die $9.0 \mathrm{~mm}$, the maximum interlocking were obtained at punch stroke $3.9 \mathrm{~mm}$.

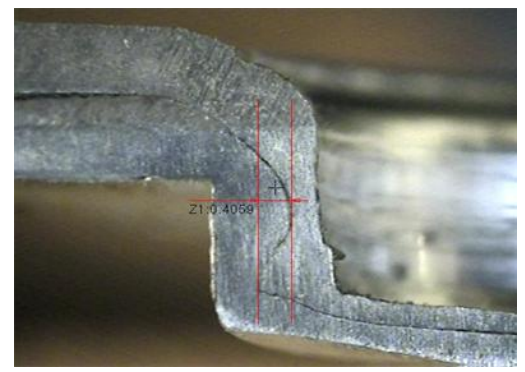

Fig. 9. Side wall interlocking.

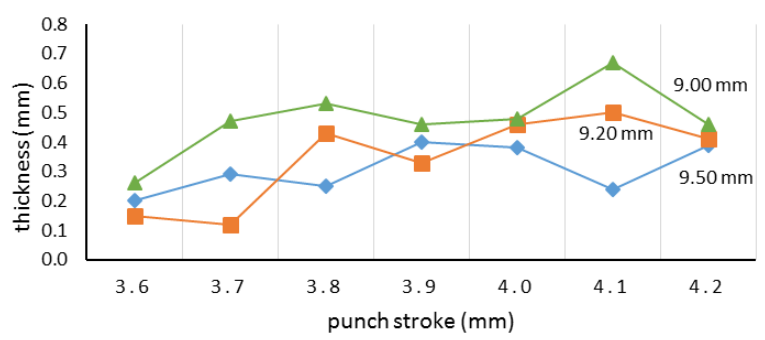

Fig. 10. Effect of punch stroke and die diameter on the interlocking.

\section{Side Wall Thickness}

For the side wall thickness, the measurement is taken at the location where the minimum thickness for the upper sheet and maximum thickness for the lower sheet is obtained. This side thickness contributes to the interlocking and shows the possibility the sheet to fracture.

Fig. 11 shows the measurement of the side wall thickness. Fig 12 illustrates the effect of different punch strokes to the thickness of sheet for the $9.00 \mathrm{~mm}, 9.20 \mathrm{~mm}$ and $9.50 \mathrm{~mm}$ die diameter. The thickness for diameter $9.2 \mathrm{~mm}$ show the most consistent result except when the stroke at $3.7 \mathrm{~mm}$. For die diameter $9.5 \mathrm{~mm}$, the thickness is $0.55 \mathrm{~mm}$ at stroke $3.6 \mathrm{~mm}$ and $4.2 \mathrm{~mm}$. but remain consistent for stroke between $3.7 \mathrm{~mm}$ and $4.1 \mathrm{~mm}$. For die with diameter of $9.0 \mathrm{~mm}$ the thickness almost the same between stroke $3.6 \mathrm{~mm}$ and $4.0 \mathrm{~mm}$, however the thickness is increase to for stroke $4.1 \mathrm{~mm}$ and $4.2 \mathrm{~mm}$.

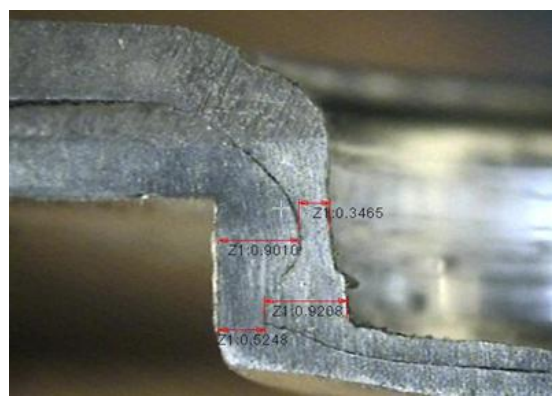

Fig. 11. Measured of side wall thickness.

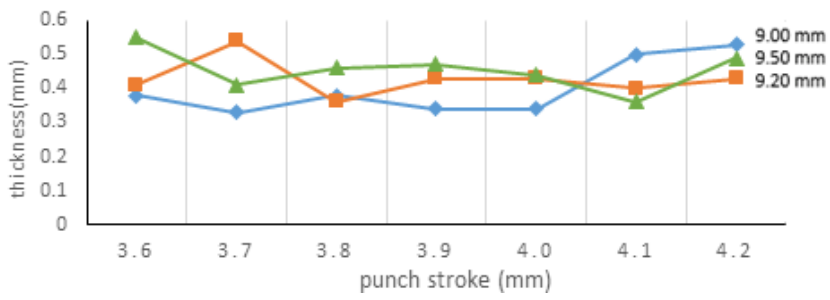

Fig. 12. Effect of thickness of side wall of sheet.

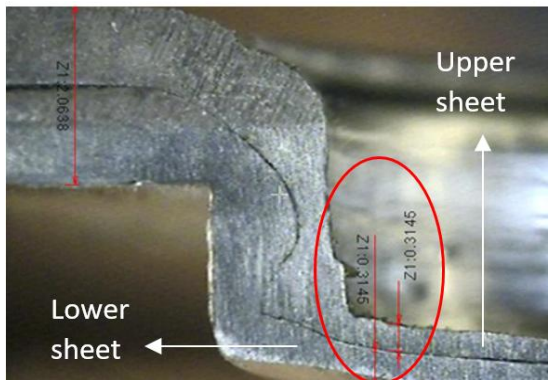

Fig. 13. Bottom wall thickness.

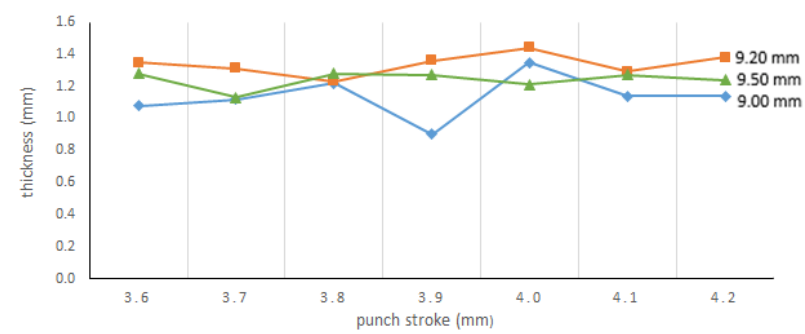

Fig. 14. Thickness of lower sheet for different strokes.

Fig. 13 shows the thickness at the bottom of the clinched sheets. Fig. 14 illustrates the thickness of lower sheet for different punch strokes with $9.00 \mathrm{~mm}, 9.20 \mathrm{~mm}$ and $9.50 \mathrm{~mm}$ die diameter. Thickness of the lower sheet for die diameter $9.5 \mathrm{~mm}$ show consistent results except when stroke at 3.7, where the thickness reduce to $1.1 \mathrm{~mm}$. For die diameter 9.2 $\mathrm{mm}$, the thickness ranging from $1.2 \mathrm{~mm}$ to $1.4 \mathrm{~mm}$. However for die diameter $9.0 \mathrm{~mm}$ give the lowest thickness $0.8 \mathrm{~mm}$.

Fracture is consider a total failure in clinching process. The sheet is fracture when the clearance is insufficient, stroke speed too fast and the surfaces of the punch or die is rough. 
Fig. 15 shows the image of the fracture at the sheet after clinching process.

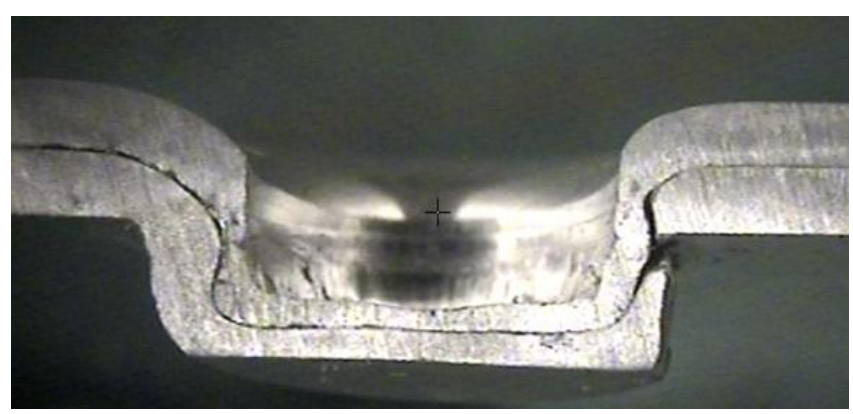

Fig. 15. Fracture after clinching process.

\section{CONCLUSION}

To join the thin aluminum sheets having, the diameter and stroke of the punch were controlled. The effect of the interlocking, wall thickness, bottom thickness and fracture of the sheet were measured. The following results were obtained: The best results of the sheet for $5.5 \mathrm{~mm}$ punch diameter, $1 \mathrm{~mm}$ thickness of aluminum sheet and $2.00 \mathrm{~mm}$ die depth are the die with diameter of $9.20 \mathrm{~mm}$ die diameter and punch stroke $4.0 \mathrm{~mm}$. With these combinations, the result for the interlocking, the side wall thickness and also the bottom thickness are within suitable range for the thickness for the sheets.

\section{REFERENCES}

[1] G. Di Franco, L. Fratini, and A. Pasta, "Influence of the distance between rivets in self-piercing riveting bonded joints made of carbon fiber panels and AA2024 blanks," Materials \& Design, vol. 35, pp. 342-349, March 2012.

[2] P. Liebig and R. Beyer, "Press Joining of Especially Coated Steel and Aluminium Sheets," Advanced Technology of Plasticity, vol. 2, Springer-Verlag, pp. 933-940, 1987.
[3] J. P. Varis, "The suitability of round clinching tools for high strength structural steel," Thin-Walled Structures, vol. 40, no. 3, 225-238, 2002.

[4] J. Varis and J. Lepistö, "A simple testing-based procedure and simulation of the clinching process using finite element analysis for establishing clinching parameters," Thin-Walled Structures, vol. 41, no. 8, pp. 691-709, 2003.

[5] Z. Hamedon, K.-I. Mori, and Y. Abe, "Hemming for joining high strength steel sheets," Procedia Engineering, vol. 81, pp. 2074-2079, 2014.

[6] K.-I. Mori, N. Bay, L. Fratini, F. Micari, and A. E. Tekkaya, "Joining by plastic deformation," CIRP Annals-Manufacturing Technology, vol. 62, issue 2, pp. 673-694, 2013.

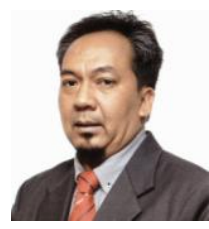

Zamzuri Hamedon was born in Pahang, Malaysia on 1972. He received Diploma in production technology from German Malaysian Institute at Kuala Lumpur, Malaysia in 1996 and obtained his B. Tech. Eng in too and die from Technology University of Tun Hussien Onn Batu Pahat, Johor, Malaysia in 2002 and M.Eng in manufacturing system engineering from National University of Malaysia in Bangi Selangor, Malaysia in 2005. He obtained his D.Eng in mechanical engineering (sheet metal forming) from Toyohashi University of Technology, Aichi, Japan in 2014.

In 1996 he began his career as CADCAM Programmer for waterjet machine at AquaCut Sdn Bhd Shah Alam, then became a Production Supervisor in 1998 at Angkasa Jasa Sdn Bhd, Cheras, Selangor, Malaysia. In 2002 he became Development Engineer at Intra Frontier Sdn Bhd in Shah Alam Selangor Malaysia. In 2002, he joined the Department of Production Technology, German Malaysia Institute Kuala Lumpur as Technical Training Officer. Since March 2007 he has been with Faculty of Manufacturing Engineering, University Malaysia Pahang, where he was Lecturer, became Senior Lecturer in 2014. Now he is holding position as Deputy Dean for Research-Innovation and Postgraduate.

His current research interests include sheet metal forming, high speed machining, EDM of composite material, product design bio-mechanic equipment and manufacturing systems engineering. He was chief editor of the International Manufacturing Engineering Conference (IMEC2015) held in November 2015 in Kuala Lumpur. For his efforts in research and invention, he was granted 3 patents and recently won an award of merit for his invention Multi-Axial Assemble in June 2016 in INPEX2016 at Pittsburgh, USA. 